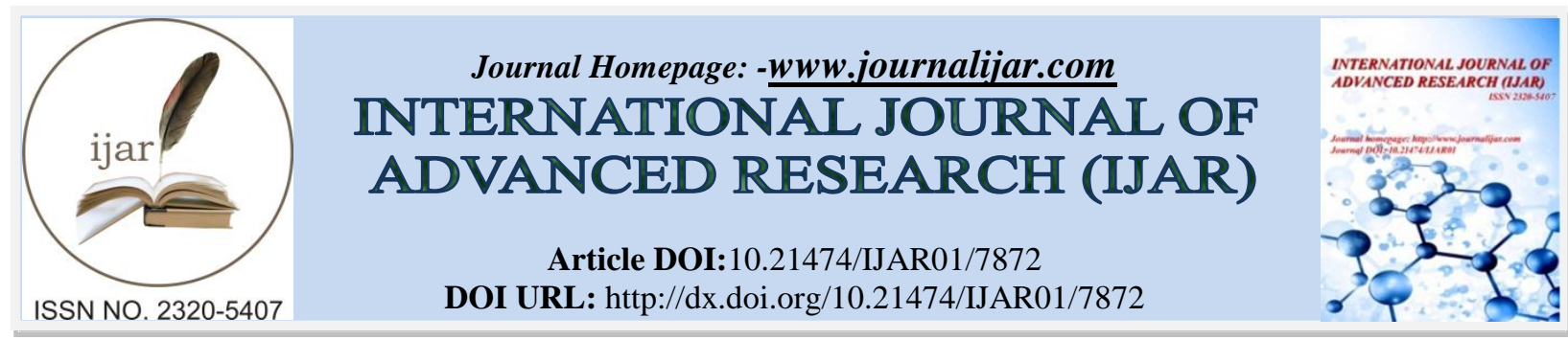

RESEARCH ARTICLE

\title{
SPONTANEOUS RENAL ALLOGRAFT RUPTURE OF UNKNOWN ETIOLOGY: A CASE REPORT.
}

\author{
Umar maqbool, Asuri krishna, V. K. Bansal, Om prakash and Subodh Kumar. \\ Renal Transplant, Dept. of Surgical Disciplines, AIIMS New Delhi.
}

\section{Manuscript Info}

Manuscript History

Received: 9 August 2018

Final Accepted: 11 September 2018

Published: October 2018

\begin{abstract}
Introduction: Rupture of renal allograft is a rare but serious complication of transplantation. This is usually attributed to acute rejection, acute tubular necrosis, or renal vein thrombosis.Some other causes like renal graft biopsy and lymphatic obstruction are also mentioned as possible causes. This usually occurs during the first 1-3 weeks following transplantation, but cases occurring as late as 72 months have been reported.

Case: A 23 yearold male with established chronic kidney disease stage 5(CKD V), underwent live related renal transplantation (LRRT) using kidney from a 46 year old donor (Mother). The laparoscopic donor nephrectomy was uneventful. Patient had an uneventful intraoperative course with usual early postoperative recovery. The patient was having a good early post operative course. On POD 2 there was sudden decrease in urine output to $100 \mathrm{ml} / \mathrm{hr}$. USG Doppler on the same day evening showed normal color flow in renal artery and renal vein. At around $7 \mathrm{pm}$, there was sudden increase in drain output with fresh blood as content (500 $\mathrm{ml}$ in $10 \mathrm{mins}$ ) with tachycardia and hypotension. In view of increased drain output, patient was taken to OR and re exploration was done. At re exploration, the renal allograft was found to have two longitudinal ruptures of around $8 \times 1 \times 2$ and $5 \times 1 \times 1$ cms(Length $\times$ Width $\times$ Depth)with active bleed. Initial attempt was made to achieve haemostasis and salvage the graft kidney, but due to uncontrolled bleed, explantation was performed. Histologyshowed features of acute tubular injury. However there was no evidence of acute rejection, ATN or vascular thrombosis.

Conclusion:This case demonstrates that early diagnosis and prompt treatment of a life-threatening condition like renal allograft rupture with explantation of the graft may be required in certain conditions as a life saving procedure.
\end{abstract}

Copy Right, IJAR, 2018,. All rights reserved.

\section{Introduction:-}

Rupture of renal allograft is a rare and serious complication following renal allograft transplantation. This usually occurs following acute rejection,acute tubular necrosis, or renal vein thrombosis [1-3]. Some other causes like renal graft biopsy and lymphatic obstruction are also mentioned as possible causes [4-5].This condition threatens the renal graft as well as patient's life. This usually presents early during the first 1-3 weeks following transplantation, but cases occurring as late as 72 months have also been reported [6]. The clinical presentation comprises of tachycardia, 
hypotension, increased drain output, graft swelling, and pain, with a significant drop in haemoglobin. Treatment consists of immediate resuscitation and re exploration, often an urgent graft nephrectomy; however, graft salvage by repair has also been performed [7-9]. We hereby report a rare case of spontaneous renal graft rupture without a diagnosed underlying cause.

\section{Case report}

A 23 year old young male with established chronic kidney disease stage5 (CKD V) secondary to chronic glomerulonephritis (CGR) was admitted for renal transplant in the month of May 2018. Patient was diagnosed with CKD two years back and was put on maintenance hemodialysis since December 2017. He underwent live related renal allograft transplantation (LRRT) on 2nd May 2018. He received a left kidney with single artery, vein and ureter from his 46 year old Mother with HLA mismatch of 2/6. It was an ABO compatible transplant with negative complement dependent cytotoxicity (CDC)and flow cytometric cross-match (FCxM). Left donor nephrectomy was done laparoscopically, the warm ischaemia time being 4 minutes. There was no injury to the renal vein or artery during donor nephrectomy. The laparoscopic donor nephrectomy was uneventful. The recipient had an uneventful intraoperative course with standard graft implantation in the right iliac fossa. Graft renal artery was anastomosed to right external iliac artery and renal vein to right external iliac vein, in end to side fashion with 6-0 prolene in continous manner.On declamping kidney was pink and turgid with brisk urine output. A modified Lich gregoir ureteroneocystostomy was made. One 18Fr drain was placed in and sheath closed back with loop nylon.

The patient was having a good post operative course. Urine output was around seven liters per day with stable vital parameters. On POD 2, in early morning hours there was sudden decrease in urine output to around $100 \mathrm{ml} / \mathrm{hr}$. Patient remained hemodynamically stable. The CVP was around 8-10 $\mathrm{cm}$ of $\mathrm{H}_{2} \mathrm{O} .500 \mathrm{ml}$ fluid challenge was given followed by a diuretic. However there was no improvement in urine output. An ultrasound Doppler was subsequently done and showed normal color flow in renal artery and renal vein. At around $7 \mathrm{pm}$, there was sudden increase in drain output with fresh blood as content $(500 \mathrm{ml}$ in $10 \mathrm{mins})$. The patient developed tachycardia with hypotension. In view of increased drain output and haemodynamic instablity, patient was urgently shifted to OR and re exploration was done. At re-exploration, the renal allograft was found to have two longitudinal ruptures of around $8 \times 1 \times 2$ and $5 \times 1 \times 1 \mathrm{cms}$ with active bleeding [Fig 1]. An attempt was made to achieve haemostasis and salvage the graft kidney using haemostatic sutures. However this was to no avail and in view of uncontrolled bleed and worsening haemodynamics of patient,explantation was performed [Fig 2]. Patient was managed in surgical ICU in immediate post operative period and shifted to ward on post operative day 1. Patient remained haemodynamically stable and was started orally on POD 1 and underwent haemodialysis on POD 2. Histopathology showed features of acute tubular injury. However there was no evidence of acute rejection, ATN or microvascular thrombosis.Renal vessels were unremarkable and no thrombus was identified. Immunostain for $\mathrm{C} 4 \mathrm{~d}$ was negative and no viral inclusions or evidence of glomerulitis was seen.

\section{Discussion:-}

Renal allograft rupture (RAR) was first reported in 1968 by Murray et al. and is defined as superficial or deep tear of the renal capsule or renal parenchyma. The prevalence of RAR ranges from $0.3 \%$ to $9 \%$ with a mean of 3.5\% [1012]. Renal allograft rupture (RAR) is usually caused by acute rejection,acute tubular necrosis, or renal vein thrombosis [1-3]. Some other causes like renal graft biopsy and lymphatic obstruction are also mentioned as possible causes [4-5]. The most frequent cause of RAR is acute graft rejection [13]. As demonstrated in this case, ruptured renal transplant susually present as an acute event with increased drain output, hypotension, tachycardia and swelling in the graft area. Treatment involves initial supportive management followed by surgical intervention with graft salvage or graft nephrectomy. Although graft salvage is possible, preservation of renal allografts following spontaneous rupture is a surgical challenge and despite successful repair, transplant nephrectomy might still be required [5,14]. In our case, the decision to perform a nephrectomy was based on multiple factors which included haemodynamic instability of the patient despite aggressive resuscitation and inability to achieve satisfactory haemostasis. Susan et al. [15] reported successful salvage in all four cases of early allograft rupture due to acute rejection concluding that transplant nephrectomy can be avoided except in the presence of uncontrollable haemorrhage. However, the outcome of salvaging attempts is shown to be rather poor in the literature. Even with successful salvage operations, often the patient ultimately requires a nephrectomy[5, 14].Patients who are haemodynamically unstable even after proper and aggressive resuscitation, graft nephrectomy should be considered the only definitive treatment $[16,17]$. 
In the present case, histological examination from the renal graft demonstrated only mild interstitial edema and insignificant interstitial inflammation, along with features of acute kidney injury. Yet the extent of graft rupture was severe and evident as a deep hemifracture of the kidney. This is consistent with the observations of Dryburgh et al [18], describing eight ruptured grafts, which were grossly tense/ edematous, however histological examination did not suggest any cellular or humoral rejection. Histopathology in this case was inconclusive and showed no evidence of acute rejection, acute tubular necrosis or microvascular thrombosis. Renal vessels were unremarkable and no thrombus was identified. Immunostain for C4d was negative. There were no viral inclusions nor evidence of any glomerulitis. J. E. Murray et al also reported in their case series of ruptured renal grafts that an apparent cause of renal allograft rupture may not be found in all cases following live related renal transplant [11].

\section{Conclusion:-}

This case demonstrates that early diagnosis and prompt treatment of a life-threatening condition like renal allograft rupture with explantation of the graft may be required in certain conditions as a life saving procedure. It may not be possible to save the ruptured graft kidney always. Although transplant nephrectomy is a definitive treatment, with advances in the surgical techniques, attempts can be made to salvage the graft if haemostasis is achieved and patient is haemodynamically stable. This is one of the few cases of graft kidney rupture without a histopathological diagnosis.

\section{Conflict of Interests}

The authors declare that there is no conflict of interests regarding the publication of this paper.

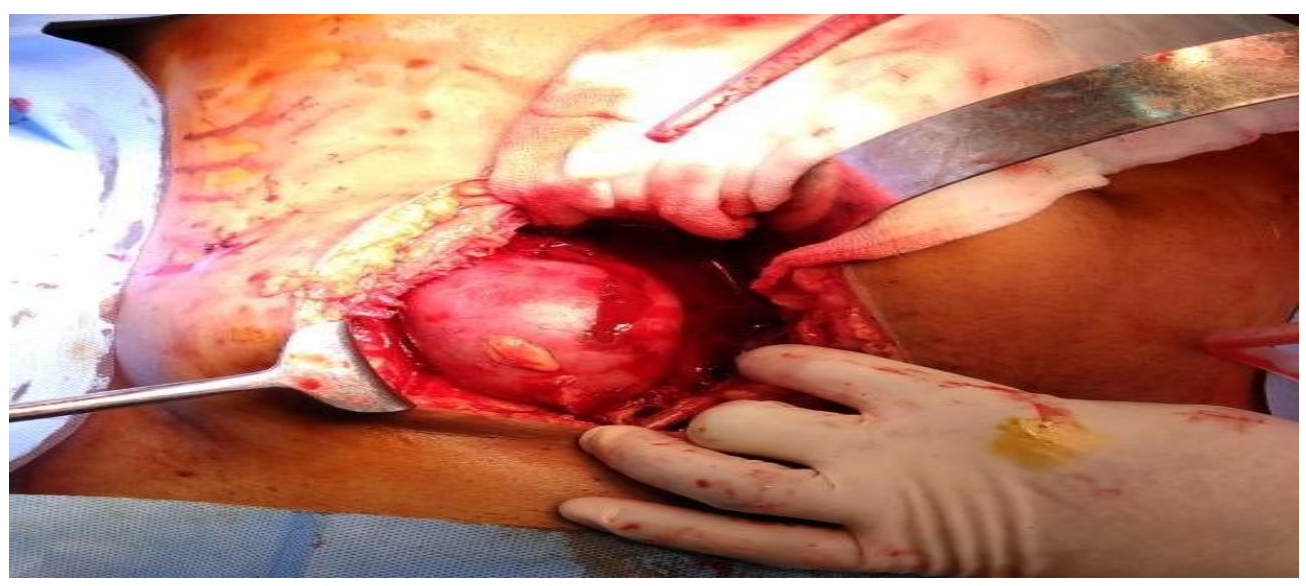




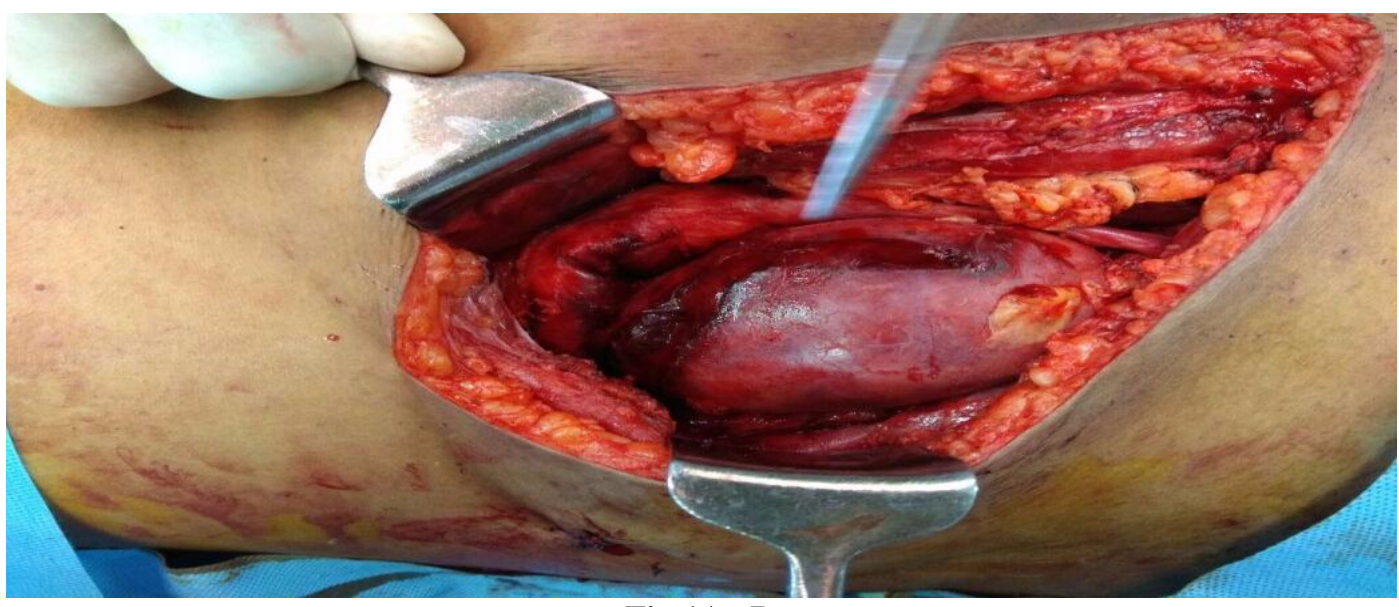

Fig 1A, B

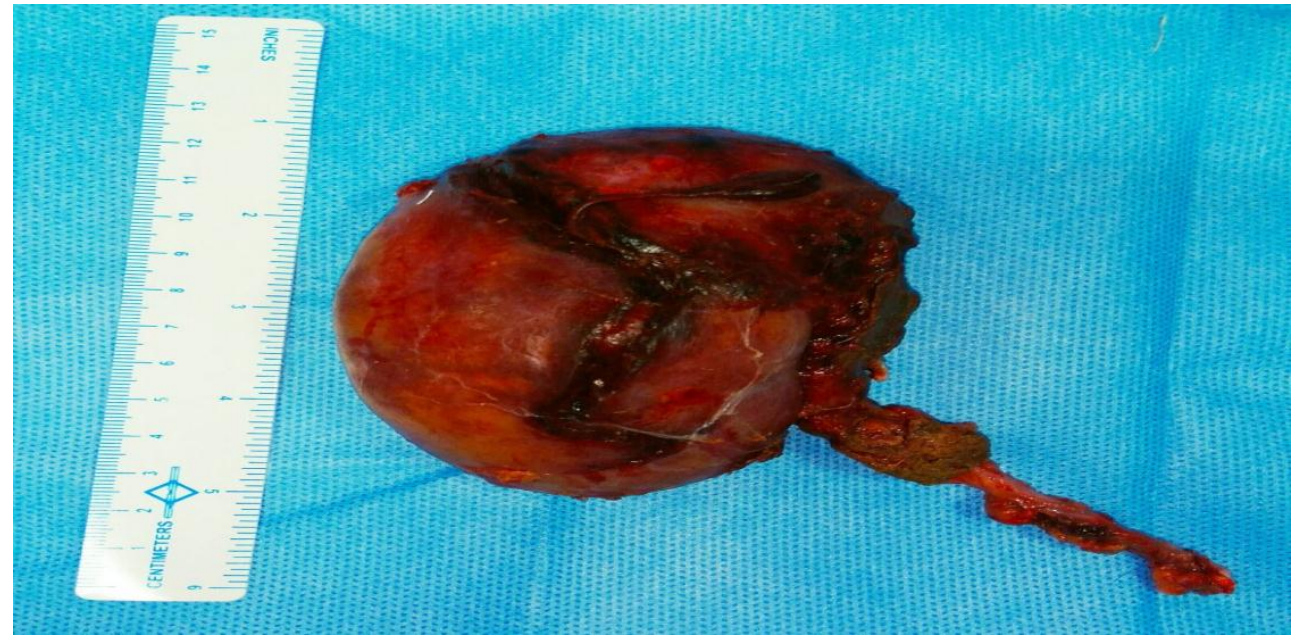

Fig 2a

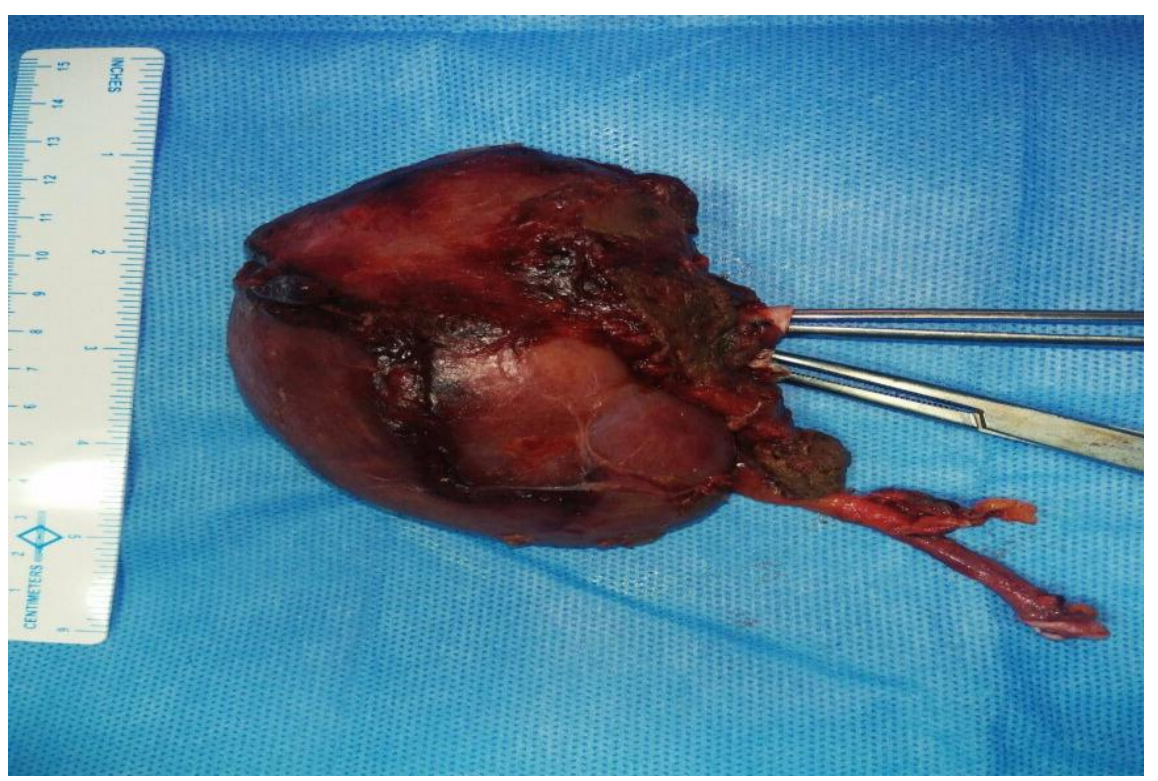

Fig 2b 


\section{References:-}

1. M. D. Garcia Sanchez de la Nieta, A. I. S'anchez-Fructuoso, R.Alc'azar et al., "Higher graft salvage rate in renal allograft ruptureassociated with acute tubular necrosis," Transplantation Proceedings, vol. 36, no. 10, pp. 3016-3018, 2004.

2. P. Szenohradszky, G. Smeh'ak, E. Szederk'enyi et al., "Renal allograftrupture: a clinicopathologic study of 37 nephrectomy casesin a series of 628 consecutive renal transplants," TransplantationProceedings, vol. 31, no. 5, pp. 2107-2111, 1999.

3. M. Ramos, L. Martins, L. Dias et al., "Renal allograft rupture: clinicopathologic review," Transplantation Proceedings, vol. 32,no. 8, pp. 2597-2598, 2000.

4. Grochowiecki T, Szmidt J, Madej K, et al: TransplantationProc 28:3461, 1996

5. Lord RS, Effeney DJ, Hayes JM, et al: Ann Surg 177:268,1973

6. S. Askandarani, N. Aloudah, H. Al Enazi, K. O. Alsaad, and A.Altamimi, "Late renal allograft rupture associated with cessationof immunosuppression following graft failure," Case Reportsin Transplantation, vol. 2011,Article ID 512893, 5 pages, 2011.

7. Y. H. Chan, K.M.Wong, K. C. Lee, and C. S. Li, "Spontaneousrenal allograft rupture attributed to acute tubular necrosis," TheAmerican Journal of Kidney Diseases, vol. 34, no. 2, pp. 355-358,1999.

8. S. Guleria, R. K. Khazanchi, A. K. Dinda et al., "Spontaneousrenal allograft rupture: is graft nephrectomy an option?" TransplantationProceedings, vol. 35, no. 1, p. 339, 2003.

9. D. S. Finley and J. P. Roberts, "Frequent salvage of ruptured renalallografts: a large single center experience," Clinical Transplantation,vol. 17, no. 2, pp. 126-129, 2003.

10. H. Shahrokh, H. Rasouli, M. A. Zargar, K. Karimi, and K.Zargar, "Spontaneous kidney allograft rupture," TransplantationProceedings, vol. 37, no. 7, pp. 3079-3080, 2005.

11. J. E. Murray, R. E. Wilson, N. L. Tilney et al., "Five years' experiencein renal transplantation with immunosuppressive drugs:survival, function, complications, and the role of lymphocytedepletion by thoracic duct fistula," Annals of Surgery, vol. 168,no. 3, pp. 416-435, 1968.

12. G. J. Azar, A. A. Zarifian, G. D. Frentz, R. J. Jesi, and E. E.Ethredge, "Renal allograft rupture: a clinical review," ClinicalTransplantation, vol. 9, pp. 71-73, 1995.

13. Hochleitner BW, Kafka R, Spechtenhauser B, et al. Renal allograft rupture isassociated with rejection or acute

14. P. G. Rosario, S. M. Greenstein,R. S. Schechner, andV. A. Tellis, "Spontaneous rupture of human renal allografts," Urology, vol.41, no. 1, pp. 21-23, 1993.

15. L. P. Susan,W. E. Braun, L. H. Banowsky, R. A. Straffon, and R.Valenzuela, "Ruptured human renal allograft pathogenesis andmanagement," Urology, vol. 11, no. 1, pp. 53-57, 1978.

16. M. Veroux, P. Veroux, C. Puliatti, P. Fiamingo, M. Macarone, and D. Cappello, "Renal allograft rupture caused by acute tubularnecrosis," ChirurgiaItaliana, vol. 55, pp. 753-755, 2003.

17. D. Heimbach, W. D. Miersch, H. Buszello, G. Schoeneich, andH. U. Klehr, "Is the transplant-preserving management of renalallograft rupture justified?" British Journal of Urology, vol. 75, no. 6, pp. 729-732, 1995.

18. Dryburgh P, Porter KA, Krom RA, et al. Should the ruptured renal allograft beremoved? Arch Surg 1979;114:850. 